\title{
Perceived Discrimination and Use of Preventive Health Services
}

\author{
Amal N. Trivedi, MD, MPH, ${ }^{1,2}$ John Z. Ayanian, MD, MPP ${ }^{1,2}$ \\ 'Division of General Medicine, Brigham and Women's Hospital, Boston, MA, USA; ${ }^{2}$ Department of Health Care Policy, \\ Harvard Medical School, Boston, MA, USA.
}

BACKGROUND: Little is known about the relation between perceptions of health care discrimination and use of health services.

OBJECTIVES: To determine the prevalence of perceived discrimination in health care, its association with use of preventive services, and the contribution of perceived discrimination to disparities in these services by race/ethnicity, gender, and insurance status.

DESIGN, SETTING, AND PARTICIPANTS: Cross-sectional study of 54,968 respondents to the 2001 California Health Interview Survey.

MEASUREMENTS: Subjects were asked about experience with discrimination in receiving health care and use of 6 preventive health services, all within the previous 12 months.

METHODS: We used multivariate logistic regression with propensityscore methods to examine the adjusted relationship between perceived discrimination and receipt of preventive care.

RESULTS: Discrimination was reported by $4.7 \%$ of respondents, and among these respondents the most commonly reported reasons were related to type of insurance $(27.6 \%)$, race or ethnicity $(13.7 \%)$, and income $(6.7 \%)$. In adjusted analyses, persons who reported discrimination were less likely to receive 4 preventive services (cholesterol testing for cardiovascular disease, hemoglobin Alc testing and eye exams for diabetes, and flu shots), but not 2 other services (aspirin for cardiovascular disease, prostate specific antigen testing). Adjusting for perceived discrimination did not significantly change the relative likelihood of receipt of preventive care by race/ethnicity, gender, and insurance status.

CONCLUSIONS: Persons who report discrimination may be less likely to receive some preventive health services. However, perceived discrimination is unlikely to account for a large portion of observed disparities in receipt of preventive care.

KEY WORDS: discrimination; disparities; preventive care; quality of care.

DOI: $10.1111 /$ j.1525-1497.2006.00413.x

J GEN INTERN MED 2006; 21:553-558.

$\mathrm{P}$ rior research has documented disparities in the use of health services based on factors such as race, gender, and insurance status. ${ }^{1-6}$ Despite this evidence, the mechanisms underlying these disparities are not fully known. One potential explanation is that these disparities may reflect discriminatory or biased practices, either on the part of providers or the system generally, that lead to certain groups receiving inadequate care.

The authors have no conflicts of interest to disclose.

Preliminary results from this study were presented at the 2004 Society of General Internal Medicine Annual Meeting in Chicago, IL, and the 2004 Academy Health Annual Research Meeting in San Diego, CA.

Address correspondence and requests for reprints to Dr. Ayanian: Department of Health Care Policy, 180 Longwood Avenue, Boston, MA 02115 (e-mail: ayanian@hcp.med.harvard.edu).
Discrimination has been defined as the "process by which a member, or members, of a socially defined group is, or are, treated differently because of his/her/their membership of that group." "Two broad levels of discrimination include structural discrimination, related to social structures and policies that determine access to goods and services for specific groups, and interpersonal discrimination that is directed toward or perceived by individuals. ${ }^{8,9}$

A growing body of research has examined the impact of experiences of discrimination on health. Prior studies have found an association between individual experiences of discrimination and high blood pressure, ${ }^{10-14}$ cigarette smoking, ${ }^{15}$ and worse self-assessed physical ${ }^{16}$ and mental health. ${ }^{17,18}$ Little is known, however, about the relation between patients' perceptions of discrimination in health care and their use of health services. A recent study found that global perceptions of discrimination were associated with delays in medical tests and pharmacy prescriptions, but this study included fewer than 600 respondents from a single county. ${ }^{19}$

Perceived discrimination could be associated with use of preventive services through 3 possible mechanisms. First, people who perceive discrimination may be less likely to seek care for routine visits at which preventive services are likely to be offered. Second, people who experience health care discrimination may lose trust in their providers, making them less likely to adhere to physicians' recommendations regarding preventive services. ${ }^{20}$ Third, patients who perceive discrimination may receive less definitive recommendations from physicians for tests and treatments. ${ }^{21}$

Our 3 study objectives were to determine the prevalence of perceived health care discrimination in a large and diverse population-based cohort, assess the association of perceived discrimination with use of preventive services, and analyze the relative contribution of perceived discrimination to observed disparities in these services by race, gender, and insurance status.

\section{METHODS}

\section{Source of Data}

We obtained data from the 2001 California Health Interview Survey (CHIS), a statewide random-digit-dial telephone survey conducted by the UCLA Center for Health Policy Research, the California Department of Health Services, and the Public Health Institute. As one of the largest health surveys in the United States, the CHIS covers topics related to access to health care, health status, and insurance, and uses a 2-stage geographically stratified sample design to produce reliable statewide population estimates. The unweighted response rate, including all attempted telephone numbers, was $43.3 \%$,

Manuscript received September 2, 2005

Initial editorial decision November 17, 2005

Final acceptance January 4, 2006 
and the cooperation rate, which includes subjects invited to participate, was $77.1 \%{ }^{22}$ These rates exceed those achieved by the CDC's Behavioral Risk Factor Surveillance System in California. ${ }^{23}$ The racial/ethnic and income characteristics of the survey respondents were closely aligned with data from the 2000 U.S. Census. ${ }^{22}$ The survey used a variety of techniques to weight the respondents to reflect the demographic characteristics of the California population according to the 2000 U.S. Census, adjust for the likelihood of having a telephone, and account for the differential probability of selecting individuals to be part of the sample.

We analyzed the adult module of CHIS, which contains data from 54,968 noninstitutionalized Californians aged 18 and older. Because our study used publicly available, deidentified data, it was deemed exempt from review by the Human Subjects Committee at Harvard Medical School.

\section{Study Variables}

The dependent variables included self-reported use of 6 preventive health services in the previous 12 months: aspirin use and cholesterol testing in adults with high blood pressure or heart disease, foot exam and hemoglobin A1c (HbAlc) testing in adults with diabetes, flu vaccine in adults age 65 or older, and prostate-specific antigen (PSA) testing in men 50 and older. These measures have been shown to improve health outcomes or have been recommended by national preventive health guidelines. ${ }^{24-28}$

The main independent variable was the following self-report of discrimination: "Thinking of your experiences with receiving health care in the past 12 months, have you felt you were discriminated against for any reason?" The survey also included a follow-up question, "What do you think was the reason you were discriminated against?," with 10 coded responses and an "other" choice. These options included age, race, language, health or disability, weight, insurance, income, gender, medical beliefs, and multiple reasons.

These survey questions were developed by UCLA researchers with assistance from Westat, a survey research organization. Pilot testing was conducted by experienced interviewers via telephone, and monitored and tape recorded by Westat and UCLA staff. Staff members debriefed respondents to evaluate their comprehension and ability to answer questions as worded. Based on the results of this pilot testing, the 2 questions to assess perceived discrimination were included in the full survey. ${ }^{29}$

\section{Statistical Analyses}

We used $\chi^{2}$ tests to assess the prevalence of discrimination in demographic and clinical subgroups and rates of preventive service use for persons reporting discrimination versus those who did not.

We used propensity score methods to control for demographic and clinical differences between persons who reported discrimination and those who did not. Propensity scores are a powerful tool to adjust for many potential confounders without specifying the relation between covariates and outcomes, as is required by more traditional modeling techniques. ${ }^{30}$

Among the population eligible for each preventive service, we first constructed logistic models predicting the propensity to report discrimination using the 12 variables listed in Table
Table 1. Proportion of Respondents Reporting Discrimination by Selected Characteristics*

\begin{tabular}{|c|c|c|}
\hline Characteristic & $\begin{array}{l}\text { Population Estimate of Number of } \\
\text { Persons Reporting Discrimination } \\
\text { (Percent of Total Population } \\
\text { within Subgroup) }\end{array}$ & $P$ Value \\
\hline Total & $1,102,054(4.7 \%)$ & \\
\hline Gender & & $<.001$ \\
\hline Male & $457,402(4.0 \%)$ & \\
\hline Female & $644,651(5.3 \%)$ & \\
\hline Age $(\mathrm{Y})$ & & $<.001$ \\
\hline 18 to 34 & $356,975(4.3 \%)$ & \\
\hline 35 to 49 & $382,296(5.4 \%)$ & \\
\hline 50 to 64 & $234,941(5.4 \%)$ & \\
\hline$\geq 65$ & $101,140(3.0 \%)$ & \\
\hline Race & & $<.001$ \\
\hline African American & 84,177 (6.1\%) & \\
\hline White & $554,373(4.2 \%)$ & \\
\hline Latino & $327,689(5.8 \%)$ & \\
\hline $\begin{array}{l}\text { American Indian/ } \\
\text { Alaska Native }\end{array}$ & 7,403 (8.8\%) & \\
\hline Asian & $76,351(2.9 \%)$ & \\
\hline Pacific Islander & $3,144(5.2 \%)$ & \\
\hline Other & $48,916(6.7 \%)$ & \\
\hline $\begin{array}{l}\text { Income (\% of Federal } \\
\text { poverty level) }\end{array}$ & & $<.001$ \\
\hline$<100$ & $252,756(7.6 \%)$ & \\
\hline 100 to 199 & $287,201(6.2 \%)$ & \\
\hline 200 to 299 & $146,625(4.4 \%)$ & \\
\hline$\geq 300$ & $415,471(3.4 \%)$ & \\
\hline Citizenship status & & .007 \\
\hline US born & 716,166 (4.4\%) & \\
\hline Naturalized & $152,776(4.8 \%)$ & \\
\hline Noncitizen & $225,956(5.6 \%)$ & \\
\hline Place of residence & & .03 \\
\hline Urban & $943,638(4.6 \%)$ & \\
\hline Rural & $154,121(5.4 \%)$ & \\
\hline $\begin{array}{l}\text { Highest educational } \\
\text { attainment }\end{array}$ & & $<.001$ \\
\hline$<12$ th grade & $228,054(6.2 \%)$ & \\
\hline High school graduate & $600,510(4.8 \%)$ & \\
\hline College graduate & 190,635 (3.9\%) & \\
\hline Postgraduate & $82,855(3.3 \%)$ & \\
\hline Marital status & & $<.001$ \\
\hline Married & 528,725 (4.1\%) & \\
\hline Not married & $568,574(5.4 \%)$ & \\
\hline English proficiency & & .002 \\
\hline Speak well/very well & $856,131(4.4 \%)$ & \\
\hline Not well/not at all & $186,939(5.8 \%)$ & \\
\hline Insurance status & & $<.001$ \\
\hline Uninsured & $284,390(7.7 \%)$ & \\
\hline Medicaid & $193,846(9.2 \%)$ & \\
\hline Employer-based & $448,909(3.5 \%)$ & \\
\hline Private & $49,480(3.7 \%)$ & \\
\hline Medicare/Medicaid & $25,301(4.3 \%)$ & \\
\hline $\begin{array}{l}\text { Medicare with } \\
\text { supplemental insurance }\end{array}$ & $57,952(2.5 \%)$ & \\
\hline Medicare only & $9,870(4.6 \%)$ & \\
\hline $\begin{array}{l}\text { Number of doctor visits in } \\
\text { past } 12 \text { months }\end{array}$ & & $<.001$ \\
\hline 0 & $145,245(3.5 \%)$ & \\
\hline 1 & $168,444(3.2 \%)$ & \\
\hline 2 & $147,651(3.6 \%)$ & \\
\hline 3 & $104,066(4.0 \%)$ & \\
\hline 4 and 5 & $152,052(5.0 \%)$ & \\
\hline$\geq 6$ & $295,165(9.3 \%)$ & \\
\hline Perceived health status & & $<.001$ \\
\hline Excellent & $124,765(2.7 \%)$ & \\
\hline Very good & $225,523(3.0 \%)$ & \\
\hline Good & $327,378(4.5 \%)$ & \\
\hline Fair & 299,696 (9.0\%) & \\
\hline Poor & $124,041(15.4 \%)$ & \\
\hline
\end{tabular}

* Numbers of subjects for each service are weighted to reflect the adult population of California.

${ }^{7} \chi^{2}$ test. 
Table 2. Most Commonly Cited Reasons for Discrimination in a Health Care Setting by Race/Ethnicity, Gender, and Insurance Type

\begin{tabular}{llll}
\hline \hline Characteristic & \multicolumn{1}{c}{ Most Common Reasons for Discrimination } \\
\cline { 2 - 4 } & \multicolumn{1}{c}{ First } & \multicolumn{1}{c}{ Second } \\
\hline Race & & & Third \\
$\quad$ African American & Race/ethnicity $(22.2 \%)$ & Insurance type (18.8\%) & Income (8.6\%) \\
White & Insurance type (33.4\%) & Age (8.2\%) & Health/disability (8.1\%) \\
Latino & Insurance type (21.5\%) & Race/ethnicity (20.5\%) & Language/accent (11.8\%) \\
Asian & Race/ethnicity (23.4\%) & Insurance type (18.7\%) & Income (5.1\%) \\
American Indian & Insurance type (19.7\%) & Income (17.1\%) & Race/ethnicity (10.5\%) \\
Sex & & Race/ethnicity (17.5\%) & Income (7.8\%) \\
Male & Insurance type (24.3\%) & Race/ethnicity (10.9\%) & Age (6.6\%) \\
Female & Insurance type (29.7\%) & Race/ethnicity (12.6\%) & Age (7.0\%) \\
Insurance status & & Race/ethnicity (16.6\%) & Income (13.4\%) \\
Insured & Insurance type (29.0\%) & Race/ethnicity (13.7\%) & Income (6.6\%) \\
Uninsured & Insurance type (23.0\%) & Insurance type (27.6\%) &
\end{tabular}

1 , as well as body mass index (BMI) and indicator variables for the presence of asthma, hypertension, heart disease, diabetes, and cancer. We included these 18 variables in the logistic models because they each had an unadjusted association $(P<.10)$ with both perceived discrimination and use of 1 or more preventive services. The propensity scores from these models were then used along with perceived discrimination as independent variables in logistic models predicting use of each preventive service for eligible patients.

To assess the impact of perceived discrimination on overall disparities in use of preventive health services by race, gender, and insurance status, we compared the odds ratios for receipt of preventive services before and after controlling for the presence of perceived discrimination. All analyses were performed using SAS version 8.2 with SAS-callable SUDAAN version 8.0 to account for the complex survey design.

\section{RESULTS}

Of the 54,968 subjects, 2,830 (4.7\%) reported having experienced discrimination in a health care setting during the previous 12 months. This finding corresponds to a population estimate of approximately 1.1 million adult Californians. Selfreported discrimination was more prevalent among most racial and ethnic minority groups, women, persons with Medicaid or no insurance, persons of lower socioeconomic status, and those in fair or poor health (Table 1). The most frequently cited reasons for discrimination (Table 2) were insurance type (27.6\%), race (13.7\%), and income (6.7\%). Discrimination related to type of insurance was the most common reason regardless of gender and insurance status and for most racial and ethnic groups.

In multivariable analyses, we found that younger age, female gender, American Indian/Alaska Native race/ethnicity, lower education, lower income, lack of insurance, having Medicaid, poor self-rated health, increasing BMI, presence of comorbid medical conditions, more frequent visits to a physician, and being unmarried were significant positive predictors of reporting discrimination (all $P<.05$ ). In this adjusted analysis, Asians were significantly less likely than whites to report discrimination, whereas African Americans and Latinos did not significantly differ from whites.

In unadjusted analyses (Table 3), persons who reported discrimination were less likely to receive all 6 preventive services, with absolute differences in utilization between persons who did and did not report discrimination ranged from $1.8 \%$ (aspirin use) to $8.6 \%$ (PSA measurement). These differences, however, were statistically significant for only HbAlc measurement, cholesterol testing, and PSA testing $(P<.05)$. After adjustment for demographic and clinical factors through the use of propensity scores, persons who experienced discrimination were significantly less likely to receive diabetic foot exams (odds ratio $[\mathrm{OR}]=0.66,95 \%$ confidence interval [95\% CI] 0.45 to 0.96), HbAlc testing (OR 0.59, 95\% CI 0.39 to 0.89), cholesterol testing (OR $0.58,95 \%$ CI 0.48 to 0.71 ), and flu vaccination (OR $0.73,95 \%$ CI 0.55 to 0.98 ). The adjusted associations between perceived discrimination and aspirin use or PSA testing were not statistically significant.

Table 3. Unadjusted and Adjusted Estimates of Preventive Health Services Use for Persons Reporting Discrimination Compared with Those Reporting No Discrimination*

\begin{tabular}{|c|c|c|c|c|}
\hline Preventive Health Service & Discrimination (\%) & No Discrimination (\%) & Adjusted Odds Ratio ${ }^{\dagger}$ & Adjusted $P$ \\
\hline Aspirin use & 33.4 & 35.2 & $0.91(0.76$ to 1.10$)$ & .32 \\
\hline Cholesterol testing & 71.0 & 79.2 & $0.58(0.48$ to 0.71$)$ & $<.001$ \\
\hline Foot exam & 60.8 & 67.6 & $0.66(0.45$ to 0.96$)$ & .03 \\
\hline Hemoglobin Alc testing & 78.5 & 86.1 & $0.59(0.39$ to 0.89$)$ & .01 \\
\hline Flu shot & 61.6 & 67.3 & $0.73(0.55$ to 0.98$)$ & .03 \\
\hline Prostate specific antigen testing & 37.1 & 45.7 & $0.85(0.61$ to 1.17$)$ & .32 \\
\hline
\end{tabular}

* Numbers of subjects for each service are weighted to reflect the adult population of California.

Odds ratios adjusted for age, sex, race, income, education, number of doctor visits in the past year, self-reported health status, insurance status, marital status, citizenship status, English proficiency, rural vs urban residence, comorbid medical conditions, and body mass index using propensity score methods. 
Table 4. Percentage of Individuals Reporting Use of Preventive Health Services by Race/Ethnicity, Gender, and Insurance Status Before and After Adjusting for Perceived Discrimination

\begin{tabular}{|c|c|c|c|c|c|c|}
\hline & \multicolumn{6}{|c|}{ Preventive health service } \\
\hline & Aspirin Use & Cholesterol Test & Foot Exam & HbAlc Test & Flu Shot & PSA Test \\
\hline \multicolumn{7}{|l|}{ Race/ethnicity } \\
\hline White (\%) & 39.5 & 79.7 & 70.3 & 89.6 & 69.8 & 50.1 \\
\hline African American (\%) & $33.0^{*}$ & $84.9^{*}$ & $79.9^{*}$ & 89.8 & $53.0^{*}$ & 45.8 \\
\hline $\mathrm{OR}^{\dagger}$ relative to whites & 0.75 & 1.43 & 1.68 & 1.02 & 0.49 & 0.84 \\
\hline Adjusted $\mathrm{OR}^{\dagger}$ & 0.76 & 1.46 & 1.74 & 1.03 & 0.50 & 0.85 \\
\hline Latino (\%) & $25.6^{*}$ & $72.6^{*}$ & $63.8^{*}$ & $76.4^{*}$ & $50.9^{*}$ & $29.5^{*}$ \\
\hline $\mathrm{OR}^{\dagger}$ relative to whites & 0.53 & 0.68 & 0.74 & 0.38 & 0.45 & 0.42 \\
\hline Adjusted OR ${ }^{\dagger}$ & 0.52 & 0.69 & 0.74 & 0.37 & 0.42 & 0.41 \\
\hline Asian (\%) & $29.5^{*}$ & 78.8 & $50.6^{*}$ & 85.2 & 71.2 & $28.9^{*}$ \\
\hline $\mathrm{OR}^{\dagger}$ relative to whites & 0.64 & 0.95 & 0.43 & 0.67 & 1.08 & 0.41 \\
\hline Adjusted $\mathrm{OR}^{\dagger}$ & 0.65 & 0.93 & 0.41 & 0.67 & 1.05 & 0.38 \\
\hline American Indian/Alaska Native (\%) & $30.2^{*}$ & 74.3 & 75.8 & $96.7^{*}$ & 64.9 & $33.4^{*}$ \\
\hline $\mathrm{OR}^{\dagger}$ relative to whites & 0.66 & 0.73 & 1.32 & 3.35 & 0.80 & 0.50 \\
\hline Adjusted OR ${ }^{\dagger}$ & 0.67 & 0.76 & 1.36 & 3.52 & 0.79 & 0.48 \\
\hline \multicolumn{7}{|l|}{ Gender } \\
\hline Male (\%) & 39.4 & 78.5 & 70.5 & 88.2 & 68.7 & N/A \\
\hline Female $(\%)$ & $31.7^{\ddagger}$ & 79.4 & $64.9^{\ddagger}$ & $83.3^{\ddagger}$ & $66.5^{\ddagger}$ & N/A \\
\hline $\mathrm{OR}^{\dagger}$ relative to males & 0.71 & 1.06 & 0.77 & 0.67 & 0.91 & $\mathrm{~N} / \mathrm{A}$ \\
\hline Adjusted $\mathrm{OR}^{\dagger}$ & 0.72 & 1.08 & 0.79 & 0.68 & 0.94 & $\mathrm{~N} / \mathrm{A}$ \\
\hline \multicolumn{7}{|l|}{ Insurance status } \\
\hline Insured (\%) & 36.4 & 81.1 & 69.5 & 88.5 & 67.6 & 47.5 \\
\hline Uninsured (\%) & $26.3^{\S}$ & $57.2^{\S}$ & $50.3^{\S}$ & $59.3^{\S}$ & $38.8^{\S}$ & $17.2^{\S}$ \\
\hline $\mathrm{OR}^{\dagger}$ relative to insured & 0.62 & 0.31 & 0.44 & 0.19 & 0.30 & 0.23 \\
\hline Adjusted $\mathrm{OR}^{\dagger}$ & 0.64 & 0.32 & 0.44 & 0.19 & 0.31 & 0.23 \\
\hline
\end{tabular}

* Different from whites $(\mathrm{P}<.05)$.

${ }^{\dagger} \mathrm{OR}$ indicates odds ratio. Adjusted $\mathrm{OR}$ indicates odds ratio after adjustment for perceived discrimination.

${ }^{\ddagger}$ Different from males $(\mathrm{P}<.05)$.

${ }^{\S}$ Different from insured $(\mathrm{P}<.05)$.

PSA, prostate specific antigen, HbA1c, hemoglobin A1c.

Relative to whites (Table 4), Latinos were less likely to receive all 6 services, African Americans were less likely to receive 4 services, and Asians and American Indians less likely to receive 3 services. Compared with men, women were less likely to receive 4 of 5 preventive health services relevant to both genders. Uninsured adults had lower rates of all 6 preventive health services compared with insured adults. Adjusting for perceived discrimination, however, had minimal effect on the OR for these subgroups and services.

\section{DISCUSSION}

In this study we assessed the relation between perceived discrimination in health care and the receipt of appropriate preventive health services in a large population-based survey. Approximately 5\% of this diverse statewide cohort reported recent experiences with discrimination in health care. Vulnerable populations, such as racial and ethnic minorities, women, persons of lower socioeconomic status and in poorer health, uninsured individuals, and Medicaid enrollees were all more likely to report discrimination, consistent with prior data from 2 Commonwealth Fund surveys in 1994 and $2001 .^{31,32} \mathrm{We}$ observed racial, gender, and insurance disparities in preventive care similar to those described in national, populationbased studies. ${ }^{33-37}$ Of note, Latinos or Asians had the lowest use of each preventive service.

We found an adjusted association between perceived discrimination and underuse of preventive services for 4 of 6 services studied. However, controlling for perceived discrimination had a minimal impact on the relative likelihood of re- ceiving preventive health services by race, gender, and insurance status. Our empirical findings suggest 2 main reasons for this seemingly paradoxical result. First, absolute rates of perceived discrimination were relatively low $(5 \%$ to $9 \%$ ), even among groups that might be expected from prior studies to experience more discrimination, including African American and Latino patients, women, and those who were uninsured or covered by Medicaid. Second, absolute differences in use of preventive services between people who did or did not report discrimination were also relatively low (1\% to $8 \%$ ). Therefore, the combination of these 2 factors may explain why perceived discrimination as measured in this survey was not an important mediator of sociodemographic disparities in use of preventive services.

The generalizability of these results to populations in other states merits discussion. California ranks last among all 50 states in spending per Medicaid enrollee, and has one of the highest rates of uninsurance. ${ }^{38}$ These factors may partially explain why insurance type was the most commonly reported reason for discrimination, and the high rates of discrimination reported among Medicaid and uninsured respondents. In addition, whites now constitute less than 50\% of the population in California. It is possible that this demographic trend may account for a lower likelihood of reporting discrimination because of race and higher rates of discrimination because of other factors such as insurance and income. Finally, California has the highest HMO penetration among all 50 states. ${ }^{38}$ The impact of managed care on perceptions of discrimination and differential rates of preventive service use is not known and deserves further investigation. 
This unique demographic and health care environment suggests that some caution should be used in extrapolating our findings to other states.

Strengths of this study included the large, representative, and diverse study population. In assessing discrimination, the survey specified a time period (12 months) and setting (health care), rather than relying on a global assessment of perceived discrimination. This approach has been recommended by previous researchers of discrimination, including those from disciplines outside of health. ${ }^{39}$ Finally, we were able to adjust for many demographic and clinical characteristics that could potentially confound the relationship between perceived discrimination and preventive care.

Study limitations included a lack of information about more specialized medical services; circumstances leading to perceived discrimination; or the intensity, frequency, and duration of perceived discrimination. In addition, the cross-sectional study design precluded causal inferences regarding discrimination and use of health services. Because relatively small proportions of respondents reported specific forms of discrimination, we were unable to test independent effects of discrimination because of insurance, race, or income. The data set also lacked information on provider characteristics that may mediate the relationship between discrimination and preventive care.

Perceived discrimination in health care is an issue that deserves more attention from researchers, providers, insurers, and policymakers. Substantial numbers of persons reported recent discrimination, particularly among those in fair or poor health who have greater unmet needs or barriers to care. ${ }^{1}$ Additional research is needed to examine the specific reasons why patients perceive health care discrimination, and whether people of different races, ethnicities, genders or socioeconomic backgrounds interpret similar clinical encounters as being discriminatory. Future studies should also compare and validate instruments to assess perceived discrimination ${ }^{40}$ and focus on discrimination in other aspects of health care, including hospital care and specialized services. This research could be used to develop and evaluate potential interventions focused on health care systems, providers, and patients to prevent discrimination in health care.

Dr. Trivedi was supported by an institutional National Research Service Award (\#5 T32 HP1 1001-15) from the Health Resources and Services Administration.

\section{REFERENCES}

1. Ayanian JZ, Weissman JS, Schneider EC, Ginsburg JA, Zaslavsky AM. Unmet health needs of uninsured adults in the United States. JAMA. 2000;284:2061-9.

2. Institute of Medicine. Coverage Matters: Insurance and Health Care. Washington, DC: National Academy Press; 2001.

3. Ayanian JZ, Epstein AM. Differences in the use of procedures between women and men hospitalized for coronary artery disease. N Engl J Med. 1991;325:221-5.

4. Ayanian JZ, Weissman JS, Chasan-Taber S, Epstein AM. Quality of care by race and gender for congestive heart failure and pneumonia. Med Care. 1999;37:1260-9.

5. Mayberry RM, Mili F, Ofili E. Racial and ethnic differences in access to medical care. Med Care Res Rev. 2000;57:108-45.
6. Smedley BD, Stith AY, Nelson AR, eds. Unequal Treatment: Confronting Racial and Ethnic Disparities in Health Care. Washington, DC: National Academy Press; 2002.

7. Jary J, Jary D. Collins Dictionary of Sociology. 2nd edn. Glasgow, UK: HarperCollins; 1995.

8. Jones CP. Levels of racism: a theoretic framework and a gardener's tale. Am J Public Health. 2000;90:1212-5.

9. Krieger N. Discrimination and health. In: Berkman L, Kawachi I, eds. Social Epidemiology. Oxford: Oxford University Press; 2000:36-75.

10. James SA, La Croix AZ, Kleinbaum DG, Strogatz DS. John Henryism and blood pressure differences among black men: the role of occupational stressors. J Behav Med. 1984;7:259-75.

11. Krieger N. Racial and gender discrimination: risk factors for high blood pressure? Soc Sci Med. 1990;30:1273-81.

12. Krieger N, Sidney S. Racial discrimination and blood pressure: the CARDIA study of young black and white adults. Am J Public Health. 1996;86:1370-8.

13. Din-Dzietham R, Nembhard WN, Collins R, Davis SK. Perceived stress following race-based discrimination at work is associated with hypertension in African-Americans. The metro Atlanta heart disease study, 1999-2001. Soc Sci Med. 2004;58:449-61.

14. Steffen PR, MCNeilly M, Anderson N, Sherwood A. Effects of perceived racism and anger inhibition on amblatory blood pressure in African Americans. Psychosom Med. 2003;65:746-50.

15. Ladrine H, Klonoff EA. The schedule of racist events: a measure of racial discrimination and study of its negative physical and mental health consequences. J Black Psychol. 1996;22:144-68.

16. Williams DR, Yu Y, Jackson J, Anderson NB. Racial differences in physical and mental health: socioeconomic status, stress, and discrimination. J Health Psychol. 1997;2:335-51.

17. Stuber J, Galea S, Ahern J, Blaney S, Fuller C. The association between multiple domains of discrimination and self-assessed health: a multilevel analysis of Latinos and blacks in four low-income New York City neighborhoods. Health Serv Res. 2003;38:1735-59.

18. Mays VM, Cochran SD. Mental health correlates of perceived discrimination among lesbian, gay, and bisexual adults in the United States. Am J Public Health. 2001;91:1869-76.

19. Van Houtven CH, Voils CI, Oddone EZ, et al. Perceived discrimination and reported delay of pharmacy prescriptions and medical tests. J Gen Intern Med. 2005;20:578-83.

20. O'Malley AS, Sheppard VB, Schwartz M, Mandelblatt J. The role of trust in use of preventive services among low-income African-American women. Prev Med. 2004;38:777-85.

21. Schulman KA, Berlin JA, Harless W, et al. The effect of race and sex on physicians' recommendations for cardiac catheterization. N Engl J Med. 1999;340:848-57.

22. California Health Interview Survey. Technical paper no 1. Available at: http://www.chis.ucla.edu/pdf/2001_response_representativeness.pdf. Accessed December 9, 2005.

23. Behavioral Risk Factor Surveillance System. Technical information and data. 2004 summary data quality report. Available at: http://www.cdc. gov/brfss/technical_infodata/2004QualityReport.htm. Accessed December 9, 2005.

24. U.S. Preventive Services Task Force. Aspirin for the primary prevention of cardiovascular events: recommendations and rationale. Ann Intern Med. 2002;136:157-60.

25. Hayden M, Pignone M, Phillips C, Mulrow C. Aspirin for the primary prevention of cardiovascular events: a summary of the evidence for the U.S. Preventive Services Task Force. Ann Intern Med. 2002; 136:157-60.

26. Smith RA, Cokkinides V, Eyre HJ. American Cancer Society guidelines for the early detection of cancer. CA Cancer J Clin. 2003;53:27-43.

27. Centers for Disease Control and Prevention. Prevention and control of influenza: recommendations of the Advisory Committee on Immunization Practices (ACIP). MMWR Recomm Rep. 2003;52:1-36.

28. American Diabetes Association. Standards of medical care for patients with diabetes mellitus. Diabetes Care. 2003;26:S33-50.

29. CHIS 2001 Methodology Series. Report 2. Data collection methods. Available at: http://www.chis.ucla.edu/pdf/CHIS2001_method2.pdf. Accessed December 9, 2005.

30. Rubin DB. Estimating causal effects from large data sets using propensity scores. Ann Intern Med. 1997;127:757-63.

31. LaVeist TA, Rolley NC, Diala C. Prevalence and patterns of discrimination among U.S. Health Care Consumers. Intl J Health Serv. 2003;33: 331-44. 
32. Blanchard $\mathbf{J}$, Lurie N. Respect: patient reports of disrespect in the health care setting and its impact on care. J Fam Pract. 2004;53:72 1-30.

33. Heisler M, Smith DM, Hayward RA, Krein SL, Kerr EA. Racial disparities in diabetes care processes, outcomes, and treatment intensity. Med Care. 2003;41:1221-32.

34. National Center for Health Statistics. Health, United States, 2004 with Chartbook on Trends in the Health of Americans. Washington, DC: U.S. Government Printing Office; 2004.

35. Nelson K, Norris K, Mangione CM. Disparities in the diagnosis and pharmacologic treatment of high serum cholesterol by race and ethnicity: data from the third National Health and Nutrition Examination Survey. Arch Intern Med. 2002;162:929-35.
36. Persell SD, Baker DW. Aspirin use among adults with diabetes: recent trends and emerging sex disparities. Arch Intern Med. 2004;164:2492-9.

37. Ward E, Jemal A, Cokkinides V, et al. Cancer disparities by race and socioeconomic status. CA Cancer J Clin. 2004;54:78-93.

38. Kaiser Family Foundation. State Health Facts. Available at: www. statehealthfacts.org. Accessed December 6, 2005.

39. Blank RM, Dabady M, Citro CF, eds. Measuring Racial Discrimination. Washington, DC: National Academy Press; 2004.

40. Krieger N, Smith K, Naishadham D, Hartman C, Barbeau EM. Experiences of discrimination: validity and reliability of a self-report measure for population health research on racism and health. Soc Sci Med. 2005;61:1576-96. 